\title{
Exploring the understanding of evidence-based concepts in people with type 2 diabetes
}

This article was published in the following Dove Press journal:

International Journal of General Medicine

20 September 2012

Number of times this article has been viewed

\author{
Tammy C Hoffmann ${ }^{1,2}$ \\ Chris B Del Mar' \\ 'Centre for Research in Evidence- \\ Based Practice, Faculty of Health \\ Sciences and Medicine, Bond \\ University, ${ }^{2}$ School of Health and \\ Rehabilitation Sciences, The University \\ of Queensland, Brisbane, Queensland, \\ Australia
}

Background: Being able to make informed decisions is a prerequisite to enabling individuals to participate actively in their health care. In turn, an individual's understanding of relevant health information can influence his/her ability to make informed decisions. However, there are two broad categories of health information, ie, background information (such as the pathophysiology of conditions) and foreground information (such as disease behavior, prognosis, and effects of treatment). Questions about foreground information are central to evidence-based practice. The majority of health literacy research has focused on background information, yet foreground information is more useful in decision-making, particularly for evidence-informed decisions. In people with type 2 diabetes, we explored individuals' knowledge of selected evidence-based concepts in diabetes; beliefs about what they can do to manage their diabetes and sources of this information; and whether these change after diabetes education.

Methods: Attendees with type 2 diabetes $(n=95)$ at a one-day diabetes educational exposition completed a questionnaire before and after the event. We asked participants about evidence-based concepts in diabetes and compared their responses with the current evidence. We also asked participants how they could best manage their diabetes, and then, how they knew this.

Results: Most participants underestimated their risk of complications. With the exception of a question about exercise and glycosylated hemoglobin level, nearly all participants provided responses that are not supported by current research evidence. There was no significant change in the percentage of participants who answered questions correctly after the exposition, except for a question about the risks of low blood glucose in which more participants answered incorrectly afterwards $(P=0.01)$. Health professionals were the most frequently identified source of information, with little value placed on research evidence.

Conclusion: Participants had a poor understanding of most of the evidence-based concepts in type 2 diabetes that were explored. This disadvantages them in being able to make informed decisions about their health care and actively manage their diabetes.

Keywords: type 2 diabetes, evidence-based practice, health literacy, patient education

\section{Introduction}

Improving health literacy is now regarded as an important factor for enabling people with chronic disease, of which type 2 diabetes is one of the most common, to take better care of themselves, assume responsibility for their illness, and improve health outcomes. ${ }^{1,2}$ People with poor health literacy are less able to manage chronic conditions, ${ }^{3}$ and in people with type 2 diabetes, inadequate health literacy is associated with worse glycemic control. ${ }^{4}$ An important component of quality diabetes care is providing education that has evolved beyond the traditional passive approach to
Correspondence: Tammy Hoffmann Centre for Research in Evidence-Based Practice, Faculty of Health Sciences and Medicine, Bond University, Gold Coast, Queensland, Australia 4229

Tel +6I 755955522

Fax $+6 \mid 75595$ I27|

Email tammy_hoffmann@bond.edu.au 
providing information that is primarily aimed at increasing an individual's adherence to health professional-defined goals and instead focuses on encouraging the active involvement of individuals in their own health care. ${ }^{5}$ Active involvement includes making decisions about health care. For these to be informed decisions, individuals need to receive clear and unbiased information. But what type of information may be most useful in assisting people to make health care decisions?

Types of information can be divided into two broad categories, ie, background information, which addresses the basic science of the organs in question, and the causes and mechanisms of the pathological processes causing the disease; and foreground information, such as the behavior of the disease, its epidemiology, prognosis, and diagnosis, and effects of treatment. Foreground information tends to be more quantitative, for example, "How much more effective is treatment A than treatment B?" Usually, foreground information will be more useful to people than background information in assisting them to make treatment choices. ${ }^{6}$

Questions that involve foreground information are central to evidence-based practice. However, in an era of patientcentered care when all efforts should be made to facilitate shared decision-making, not only do clinicians need to understand foreground concepts, but their patients also. This can enable patients to understand issues such as the size of the benefit that can be expected from a particular treatment, the risk of side effects from a certain treatment, the likelihood of complications for a particular health condition, how this type of knowledge is generated, and which types of knowledge are more trustworthy. There are various definitions of health literacy, and in its traditional sense, it has been defined as "the degree to which individuals have the capacity to obtain, process, and understand the basic information needed to make appropriate decisions about their health". ${ }^{7}$ While there has been much research in the field of health literacy, very little research has explored the foreground information component of health literacy and investigated the extent to which patients understand these concepts.

In a qualitative study of people with diabetes, most participants reported not receiving enough or any information about the benefits and risks of treatments, but their knowledge and beliefs about the benefits and risks were not explored. ${ }^{8}$ Diabetes organizations, including consumer health organizations, have become leaders in providing information to people with diabetes to the extent that health professionals refer more often to diabetes consumer health organizations than to other chronic disease consumer health organizations, ${ }^{9}$ and individuals with diabetes report turning to such organizations to fill their knowledge gaps. ${ }^{8}$

The evaluation of a diabetes educational exposition (expo) organized by the state branch of Australia's leading diabetes consumer health organization afforded an opportunity to sample people with type 2 diabetes, and explore: their knowledge of selected foreground concepts in diabetes and compare this with the actual evidence; what they believed they could do to make the most difference to their diabetes, together with the sources of that information; and whether this knowledge and these beliefs changed after attending the diabetes educational expo.

\section{Materials and methods}

Participants were attendees at a locally advertised one-day diabetes educational community expo in Brisbane, Australia in 2010. The event consisted of a series of educational lectures presented by a range of health professionals, including a diabetes educator, general practitioner, podiatrist, optometrist, exercise physiologist, dietician, and psychologist. Attendees with a self-declared diagnosis of diabetes were invited to participate in this study at registration on the day of the event and provided informed consent. They selfcompleted a pre-expo questionnaire. At the end of the day, they self-completed an identical post-expo questionnaire. The study was approved by a University of Queensland ethics committee (2009001578).

The questionnaire contained five sections. The first section contained questions about demographic and clinical details (age, gender, number of years of education completed, type of diabetes, duration of diabetes). The second section contained questions that assessed knowledge about diabetes and these are shown in Figure 1 and Table 2. Participants were also asked the following two-part open-ended question: "What are the things that you can do that will make the most difference to your diabetes and your health?" and "How do you know this?" The remaining sections of the questionnaire consisted of existing validated measures of self-efficacy, self-management, and empowerment to manage diabetes, the results of which are reported elsewhere. ${ }^{10}$

The data were analyzed using SPSS version 18 (SPSS Inc, Chicago, IL). Responses to the fixed-response knowledge questions were dichotomized into correct or incorrect, and McNemar's Chi-square was used to test the significance of the change in the proportion of correct answers from pre-expo to post-expo for questions $2-5$. To categorize responses to the open-ended questions, responses with multiple themes were separated into individual response items, and initially 


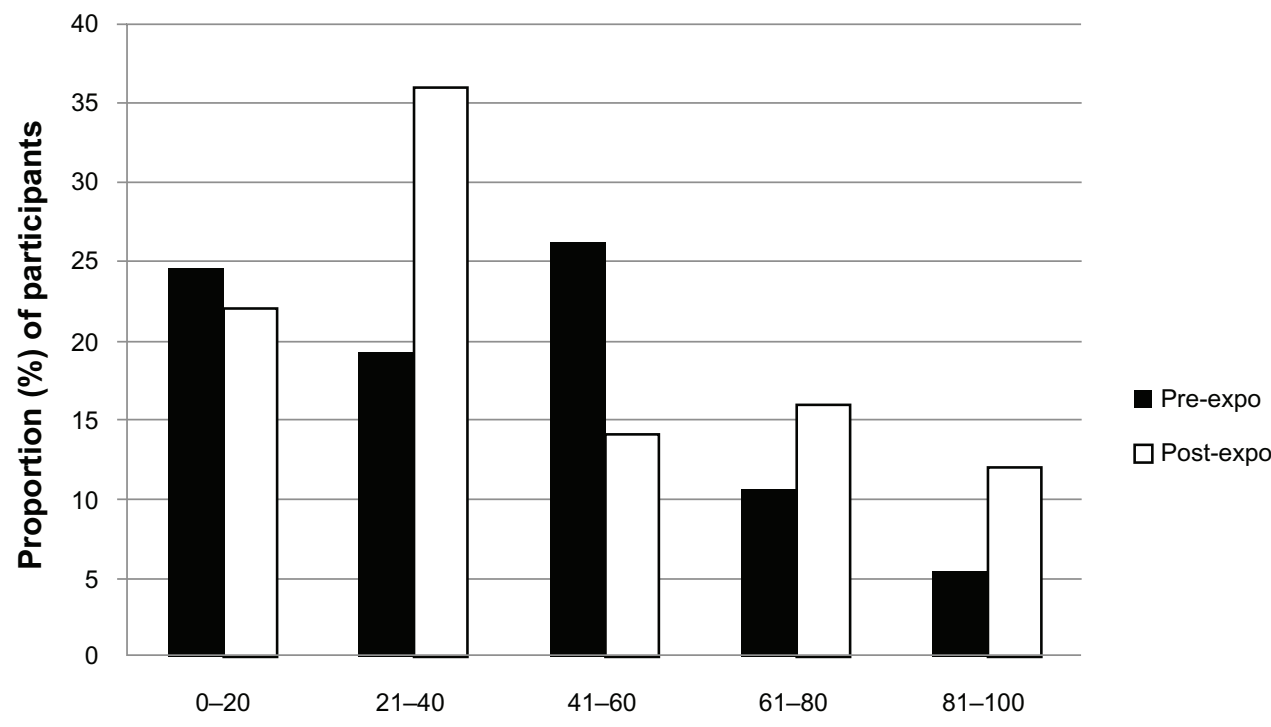

\section{Estimates of the number of people, out of 100 , with diabetes-related eye complications at 15 years}

Figure I Participant estimates, pre-expo and post-expo, of the number of people with type 2 diabetes who will develop eye complications after 15 years.

coded items using the direct wording of the response to group similar emerging themes into categories. ${ }^{11}$ The initial categories were independently reviewed and refined, and the data were then re-examined to check their final categorization, and whether the concepts adequately described participant responses.

\section{Results}

Although attendees at the expo included people with type 1, type 2, gestational, and pre-diabetes, only responses from participants with type 2 diabetes were analyzed for this study. Paired pre-expo and post-expo questionnaires were completed by 95 people with type 2 diabetes, of a total of 103 , giving a response rate of $92 \%$. An additional five people with type 1 diabetes completed the questionnaire. Table 1 shows the demographic characteristics of the study participants.

Table I Participant characteristics

\begin{tabular}{ll}
\hline Characteristic & $\begin{array}{l}\text { Participants } \\
(\mathbf{n}=\mathbf{9 5})\end{array}$ \\
\hline Female, $\mathrm{n}(\%)$ & $49(52)$ \\
Age & $3(3)$ \\
$\quad<45$ years, $\mathrm{n}(\%)$ & $46(48)$ \\
$45-65$ years, $\mathrm{n}(\%)$ & $3 \mathrm{I}(33)$ \\
$66-75$ years, $\mathrm{n}(\%)$ & $15(16)$ \\
$>75$ years, $\mathrm{n}(\%)$ & $8.9(6.5, \mathrm{I}-28)$ \\
Mean duration $($ years) of type 2 diabetes (SD, range) & $10.7(2.5,6-18)$ \\
Mean years of formal education completed (SD, range) &
\end{tabular}

Responses to question 1 (participant estimates of the incidence of diabetes-related eye complications) are shown in Figure 1. The incidence of eye complications derived from the literature is approximately $78 \%$ at 15 years from diagnosis, ${ }^{12}$ but the majority of participants underestimated this, at both points in time.

The proportion of participants whose responses to questions 2-5 are supported by current research evidence are presented in Table 2, along with the key references for each of the questions. The change in the proportion of participants who answered correctly was statistically significant for question $5(P=0.01)$, but not for questions $2-4$.

Participants who answered yes to question 5 (Table 2) were asked to elaborate on what they thought the risks were. Most listed hypoglycemia (34 pre-expo, 43 post-expo) or a symptom of hypoglycemia (13 pre-expo, four post-expo). A small number of participants thought that there were risks without being able to identify them specifically (four pre-expo, three post-expo), or listed risks that included heart problems, kidney failure, or eye complications (three both pre-expo and post-expo).

Participant responses to the two-part open-ended question are shown in Tables 3 and 4. The majority of participants responded, at both points in time, with responses that were about having a healthy lifestyle, such as healthy eating and doing regular exercise. Ten participants whose response was a healthy lifestyle-related response pre-expo did not respond similarly post-expo: six were now unsure what they could do; 
Table 2 Proportion of participants, pre-expo and post-expo, who answered questions 2-5 in line with the evidence and the key references for such evidence

\begin{tabular}{|c|c|c|c|}
\hline \multirow[t]{2}{*}{ Question } & \multicolumn{2}{|c|}{ Participants answering correctly (\%) } & \multirow[t]{2}{*}{ Key reference/s } \\
\hline & Pre-expo & Post-expo & \\
\hline $\begin{array}{l}\text { 2. How can regular physical activity affect } \\
\text { your } \mathrm{HbA}_{\mathrm{IC}} \text { level? }\end{array}$ & 86 & 87 & $\begin{array}{l}\text { Exercise reduces } \\
\mathrm{HbA}_{\mathrm{IC}} \text { by } 0.6 \%{ }^{17}\end{array}$ \\
\hline $\begin{array}{l}\text { 3. If you have type } 2 \text { diabetes, self-monitoring } \\
\text { your blood glucose helps you to have } \\
\text { better blood glucose level control. }\end{array}$ & 5 & 2 & RCT found no benefit ${ }^{19}$ \\
\hline $\begin{array}{l}\text { 4. If you have type } 2 \text { diabetes, keeping your } \\
\text { blood sugar as low as possible will reduce } \\
\text { your risk of complications. }\end{array}$ & 1 & 2 & $\begin{array}{l}\text { Two RCTs found no benefit } \\
\text { from intensive glucose control }{ }^{20,21}\end{array}$ \\
\hline $\begin{array}{l}\text { 5. Are there any risks to keeping your } \\
\text { blood sugar as low as possible? }\end{array}$ & 66 & 51 & Yes $^{21}$ \\
\hline
\end{tabular}

Abbreviations: $\mathrm{HbA}_{\mathrm{IC}}$, glycosylated hemoglobin; $\mathrm{RCT}$, randomized controlled trial.

and four thought they should increase glucose monitoring. The most frequently reported source of knowledge identified was from health professionals, increasing after the expo.

\section{Discussion}

This is the first study to explore individuals' knowledge of selected foreground concepts in diabetes and compare this with the actual evidence. Adequate understanding of these concepts is a prerequisite to individuals being able to participate actively in their health care, take responsibility for their own health care, and take part in informed decisionmaking.

Most participants underestimated the risk of eye complications (question 1) even after the high risk was communicated in the education sessions. Patients commonly underestimate risks associated with their chronic illness and its management. ${ }^{13,14}$ There are implications of this. In particular, it means that if perception of risk drives behavior change, then underestimates of risk will fail to motivate individuals sufficiently towards healthier behavior. Question 5 also assessed risk knowledge, and at the conclusion of the expo, more participants failed to realize that there are risks to keeping blood sugars as low as possible than at the beginning of the expo. This may have been due to shortcomings in the educational process, which instead created more uncertainty or confusion. If so, this is an urgent problem, and patient education should not leave more people with incorrect perceptions. There is a range of individual and social factors which influence how individuals perceive risk, ${ }^{15}$ and the difficulties in effectively communicating risk have been acknowledged. ${ }^{15,16}$ Clearly the didactic method used at the expo was not effective in improving participant knowledge about risk.

In contrast with most other knowledge questions which were answered incorrectly by the majority, most participants knew that exercise may reduce their glycosylated hemoglobin level, even before attending the expo. Speculating on reasons for this well understood information might include

Table 3 Categorized responses to the question "What are the things that you can do that will make the most difference to your diabetes and your health?"

\begin{tabular}{|c|c|c|c|}
\hline \multirow[t]{2}{*}{ Category } & \multicolumn{2}{|l|}{$n^{*}$} & \multirow[t]{2}{*}{ Illustrative quotes } \\
\hline & Pre-expo & Post-expo & \\
\hline Healthy lifestyle behaviors & 84 & 82 & \\
\hline - Regular exercise & 75 & 72 & Exercising daily \\
\hline - Healthy eating & 64 & 62 & Watching what I eat \\
\hline - Maintaining a healthy weight & 13 & 12 & \\
\hline - Do not smoke/cease smoking & 1 & I & \\
\hline Regular checkups with a health professional & 8 & 13 & Regular checks with my doctor \\
\hline Monitor glucose level frequently & 13 & 14 & Monitor my blood sugar frequently \\
\hline Take medication & 5 & 6 & Take my medication as told \\
\hline Unsure & 2 & 4 & Don't know \\
\hline Having a positive attitude & 2 & 4 & Having a positive outlook \\
\hline Being knowledgeable about diabetes & 3 & 2 & Being educated about how to live with diabetes \\
\hline
\end{tabular}

Note: *Total number of responses exceeds the sample size as some participants provided more than one response to this question. 
Table 4 Categorized responses to the question "How do you know this"?

\begin{tabular}{|c|c|c|c|}
\hline \multirow[t]{2}{*}{ Category } & \multicolumn{2}{|l|}{ n* } & \multirow[t]{2}{*}{ Illustrative quotes } \\
\hline & Pre-test & Post-test & \\
\hline \multirow[t]{2}{*}{ Told by a health professional } & 32 & 57 & Doctor keeps saying it \\
\hline & & & Advice from a dietician \\
\hline From own experience and feedback & 20 & 16 & Because if I eat wrong I feel the difference \\
\hline from doing/not doing something & & & Have practiced doing these strategies and got good results \\
\hline Have sought out my own information & 20 & 8 & From reading l've found and done \\
\hline \multirow[t]{2}{*}{ Gut feeling } & 6 & 4 & Just know \\
\hline & & & Because I know it is the right thing \\
\hline
\end{tabular}

Note: *Total number of responses exceeds sample size because some participants provided more than one response to this question.

this information being well established ${ }^{17}$ and having simply diffused into the general population. Perhaps also, the knowledge is intuitive. People may better accommodate thinking about tangible models and their analogies (background information), than the more abstract concepts inherent in understanding the outcomes of research studies (foreground information), which is what an evidence-based (empirical) approach would demand. If true, this means that empirical evidence (foreground information) should be clothed in mechanism-based explanations (background information) in attempts to improve health literacy. A randomized trial that communicated the benefits and risks of anticoagulant medication found that using evidence in the form of patient anecdotes was more effective at improving patients' knowledge than using empirical evidence. ${ }^{18}$ Further research that identifies the most effective methods of communicating evidence to patients is needed.

Current research evidence ${ }^{19-21}$ does not support the responses given by almost all participants, both before and after the expo, to questions 3 and 4 . One reason may be the novelty of this evidence, which may not be known or accepted by the health professionals who presented at the expo. This evidence, and the implications for diabetes care, remains controversial in the literature ${ }^{22-24}$ and has created confusion among health professionals. It is not surprising that individuals with diabetes are also either unaware or confused. Another reason may be the counter-intuitiveness of the results of these recent studies and the lack of a tangible background model that can be used to explain them.

Participants described their intention to implement what they believed they could do to manage their diabetes effectively. Most had addressed healthy lifestyle behaviors even before the expo. This is encouraging, even though such intentions may not follow through to improved behavior. An important minority of participants appeared to delegate their health responsibilities to their clinicians, as if they trusted the medical model to solve their health needs. This is a concern $^{25,26}$ because people who attend such an expo might be a selected group more interested in taking responsibility for their health.

The most frequently identified source of information was a health professional, while the next most common was self-awareness, either from individual experimentation or a "gut feeling". Only a small number of participants suggested an independent process, such as reading or searching the Internet. Again, this reflects a traditional model of medical decision-making where individuals rely on expert opinion ${ }^{5}$ rather than the preferred patient-centered model of care that involves a more equal discourse between the health professional and patient, with the seeking of information being under the control of patients rather than being received passively. ${ }^{25,26}$ It has been previously reported ${ }^{8}$ that when making a decision, individuals with diabetes use knowledge from experimentation or experience with a treatment, rather than consciously assessing the benefit and risk of a treatment, and the results of the current study support this.

Relying on "gut feeling" and placing little value on scientific evidence has been found in studies that have explored the decision-making processes in people with cancer ${ }^{27}$ and individuals considering undergoing screening for prostate cancer. ${ }^{28}$ Components of health literacy include understanding how knowledge is generated, and that some sources of knowledge are more trustworthy and hence better for decision-making. We need to understand how to incorporate such foreground information optimally into educational interventions to achieve this, thereby enabling people with diabetes to engage effectively in shared decision-making.

There are some limitations to this study. Participants were likely a small minority of those sufficiently motivated to attend an educational expo and as such may not be representative of the general population of people with type 2 diabetes. The concept of patient understanding of evidencebased concepts is an underexplored area in traditional health literacy research and no measures to assess this concept have 
been developed. We selected some key concepts to explore and compare patient knowledge of the evidence; however, participant knowledge may not have been accurately assessed by the knowledge questions, and the responses may not predict actual behavior. Nevertheless, these findings provide some new insights.

\section{Conclusion}

Participants had a poor understanding of most of the foreground concepts of diabetes that were explored in this pilot study. This would place them at a disadvantage in terms of being able to make informed decisions about their health care. ${ }^{6}$ As the clinical options and amount of information available to people with diabetes continues to expand, the need for individuals to be able to digest foreground information and use it to participate actively in their health care and decision-making will also grow in importance. The challenge of how to meet this need and incorporate it into quality diabetes care remains.

\section{Acknowledgments}

We gratefully acknowledge the assistance of Jane O'Shea of the University of Queensland in collecting data for this study. TH is supported by a National Health and Medical Research Council/Primary Health Care Research Evaluation and Development Career Development Fellowship (1033038) with funding provided by the Australian Department of Health and Ageing.

\section{Disclosure}

The authors report no conflicts of interest in this work.

\section{References}

1. Adams RJ, Appleton SL, Hill CL, Dodd M, Findlay C, Wilson DH. Risks associated with low functional health literacy in an Australian population. Med J Aust. 2009;191:530-534.

2. Adams RJ, Stocks NP, Wilson DH, et al. Health literacy - a new concept for general practice? Aust Fam Physician. 2009;38:144-147.

3. DeWalt D, Berkman ND, Sheridan S, Lohr KN, Pignone MP. Literacy and health outcomes: a systematic review of the literature. J Gen Intern Med. 2004;19:1228-1239.

4. Schillinger D, Grumbach K, Piette J, et al. Association of health literacy with diabetes outcomes. JAMA. 2002;288:475-482.

5. Muhlauser I, Berger M. Evidence-based patient information in diabetes. Diab Med. 2000;17:823-829.

6. Irwig L, Irwig J, Trevena L, Sweet M. Smart Health Choices - Making Sense of Health Advice. Sydney, Australia: Allen and Unwin; 2007.

7. Institute of Medicine. Health Literacy: A Prescription to End Confusion. Washington, DC: The National Academies Press; 2004.

8. Nair KM, Levine MA, Lohfeld LH, Gerstein HC. "I take what I think works for me": a qualitative study to explore patient perception of diabetes treatment benefits and risks. Can J Clin Pharmacol. 2007;14: e251-e259.
9. Boyle FM, Mutch AJ, Dean JH, Dick ML, Del Mar CB. Consumer health organisations for people with diabetes and arthritis: who contacts them and why? Health Soc Care Community. 2009;17:628-635.

10. Hoffmann T, O'Shea J. An evaluation of the effectiveness of a brief self-management educational expo provided by a consumer health organisation for people with type 2 diabetes. Educ Ther Patient. 2012;4:41-46.

11. Corbin J, Strauss A. Basics of Qualitative Research. 3rd ed. Thousand Oaks, CA: Sage Publications; 2008.

12. Klein R, Klein B, Moss S, Davis M, DeMets D. The Wisconsin epidemiologic study of diabetic retinopathy. III. Prevalence and risk of diabetic retinopathy when age at diagnosis is 30 or more years. Arch Ophthalmol. 1984;102:527-532.

13. Siegel CA, Levy LC, Mackenzie TA, Sands BE. Patient perceptions of the risks and benefits of infliximab for the treatment of inflammatory bowel disease. Inflamm Bowel Dis. 2008;14:1-6.

14. Habib S, Sonoda L, See T, Ell P, Groves A. How do patients perceive the benefits and risks of peripheral angiosplasty? Implications for informed consent. J Vasc Interv Radiol. 2008;19:177-181.

15. Alaszewski A, Horlick-Jones T. How can doctors communicate information about risk more effectively? BMJ. 2003;327:728-731.

16. Edwards A, Thomas R, Williams R, Ellner A, Brown P, Elwyn G. Presenting risk information to people with diabetes: evaluating effects and preferences for different formats by a web-based randomised controlled trial. Patient Educ Couns. 2006;63:336-349.

17. Thomas DE, Elliott EJ, Naughton GA. Exercise for type 2 diabetes mellitus. Cochrane Database Syst Rev. 2006;3:CD002968.

18. Mazor K, Baril J, Dugan E, Spencer F, Burgwinkle P, Gurwitz J. Patient education about anticoagulant medication: is narrative evidence or statistical evidence more effective? Patient Educ Couns. 2007;69:145-157.

19. Farmer A, Wade A, Goyder E, et al. Impact of self monitoring of blood glucose in the management of patients with non-insulin treated diabetes: open parallel group randomised trial. BMJ. 2007;335:132.

20. Duckworth W, Abraira C, Moritz T, et al. Glucose control and vascular complications in veterans with type 2 diabetes. $N$ Engl $J$ Med. 2009;360:129-139.

21. Gerstein HC, Miller ME, Byington RP, et al. Effects of intensive glucose lowering in type 2 diabetes. $N$ Engl J Med. 2008;358:2545-2559.

22. McCormack J, Greenhalgh T. Seeing what you want to see in randomised controlled trials: versions and perversions of UKPDS data. United Kingdom prospective diabetes study. BMJ. 2000;320:1720-1723.

23. Malanda U, Welschen L, Riphagen I, Dekker J, Nijpels G, Bot S. Self-monitoring of blood glucose in patients with type 2 diabetes mellitus who are not using insulin. Cochrane Database Syst Rev. 2012;1: CD005060.

24. ADVANCE Collaborative Group. Intensive blood glucose control and vascular outcomes in patients with type 2 diabetes. $N$ Engl J Med. 2008;358:2560-2572.

25. Stott NCH, Davis RH. The exceptional potential in each primary care consultation. J R Coll Gen Pract. 1979;29:201-205.

26. Charles C, Gafni A, Whelan T. Shared decision-making in the medical encounter: what does it mean? (or it takes at least two to tango). Soc Sci Med. 1997;44:681-692.

27. Verhoef MJ, Trojan L, Armitage GD, Carlson L, Hilsden RJ. Complementary therapies for cancer patients: assessing information use and needs. Chronic Dis Can. 2009;29:80-88.

28. Farrell MH, Murphy MA, Schneider CE. How underlying patient beliefs can affect physician-patient communication about prostate-specific antigen testing. Eff Clin Pract. 2002;5:120-129. 
International Journal of General Medicine

Dovepress

\section{Publish your work in this journal}

The International Journal of General Medicine is an international, peer-reviewed open-access journal that focuses on general and internal medicine, pathogenesis, epidemiology, diagnosis, monitoring and treatment protocols. The journal is characterized by the rapid reporting of reviews, original research and clinical studies across all disease areas.
A key focus is the elucidation of disease processes and management protocols resulting in improved outcomes for the patient. The manuscript management system is completely online and includes a very quick and fair peer-review system. Visit http://www.dovepress.com/ testimonials.php to read real quotes from published authors.

Submit your manuscript here: http://www.dovepress.com/international-journal-of-general-medicine-journal 